\title{
QUAIS DIREITOS POLÍTICOS PARA AS CIDADÃS DA ATENAS CLÁSSICA? ${ }^{1}$
}

\author{
Violaine Sebillotte Cuchet ${ }^{2}$
}

\begin{abstract}
Resumo: Durante muito tempo, predominou a visão de que as mulheres na antiguidade grega e, mais especificamente, na Atenas Clássica, estavam excluídas da política. No entanto, nos últimos vinte anos, estudos utilizando as mais diversas fontes tem destacado a capacidade das mulheres de atuar no espaço público e agir politicamente. Observaremos nesse artigo as possibilidades dessa atuação ao suscitar reflexões sobre o que os gregos entendiam por pólis (cidade), politikè (política), politeia (regime, cidadania) e politai (cidadãos).
\end{abstract}

Palavras-chave: Gênero; Atenas Clássica; Mulheres; Cidadania; Política.

Nos anos 1990, a ideia amplamente dominante era a da exclusão das mulheres da política, um fenômeno apresentado como original, duradouro e estável até o início do século XX. Esta ideia, ainda generalizada e correta se aderirmos à definição moderna e europeia da cidadania ${ }^{3}$, e que se inscreve em uma perspectiva evolucionista, foi sustentada por uma brilhante historiografia, notadamente na França e no meio dos especialistas da antiguidade. Para este período da história, só recentemente as críticas oriundas, sobretudo, dos Estados Unidos e da Europa do Norte, foram ouvidas. Utilizando as mais diversas fontes - documentos ditos da prática - os trabalhos realizados desde os anos 2000 sublinharam ao mesmo tempo a capacidade de ação das mulheres no espaço público e a existência de uma declinação feminina no vocabulário da cidadania. ${ }^{4}$ No entanto, continua a ser difícil passar da constatação da existência de um vocabulário simétrico para cidadãos e cidadãs à conclusão de que essas últimas podiam agir politicamente. Ainda assim, a importância dos

1 Tradução de Cláudia Beltrão da Rosa (UNIRIO)

2 Professora de História Antiga da Université Paris 1 Panthéon-Sorbonne.

3 Para uma visão da definição ocidental de cidadania, ver BARTHÉLÉMY \& CUCHET (2016, pp. 7-22), que introduz o tema do número: Citoyennetés.

4 Para um balanço recente: CUCHET, 2016, pp. 187-217. 
resultados trazidos pela abordagem antropológica no estudo da política antiga, por um lado, e o desenvolvimento de pesquisas sobre as sociedades helenísticas e do Oriente romano, por outro, que trouxeram aos classicistas um material (as inscrições) do qual eles faziam pouco uso, abriram perspectivas inéditas para os questionamentos sobre a história das mulheres e do gênero.

Um manual francês recente de ciências econômicas e sociais define os "direitos políticos" como "o direito de sufrágio e o direito de eleição", direitos que são por vezes designados como "direitos cívicos" e opostos aos "direitos civis". Para quem se atém a esta definição contemporânea dos "direitos políticos", a questão de saber se tais direitos foram concedidos às mulheres da antiguidade grega não tem qualquer pertinência: nenhuma mulher votava na assembleia. Pode-se sublinhar, contudo, a fecundidade heurística da questão quando ela permite perguntar pelo conjunto do fato político nas cidades gregas, isto é, de lhe descentrar. ${ }^{6} \mathrm{O}$ que é que os gregos colocavam por trás das palavras polis (cidade), politikè (política), politeia (regime, cidadania), politai (cidadãos)? ${ }^{7}$ Que parte cabia aos direitos? Que parte aos atos? Que parte às competências? Para encontrar os contornos dessas realidades antigas é necessário, ao mesmo tempo, desconstruir os pressupostos modernos sobre o lugar das mulheres na antiguidade clássica e sobre o que significava ser cidadão em uma cidade como Atenas (a mais documentada). Isso permitirá propor uma descrição do agir politico que é mais adequada às práticas antigas.

\section{Perspectiva contemporânea: As mulheres excluídas da POLÍtica}

É geralmente admitido que as mulheres das cidades gregas fossem eternas menores, sempre representadas por um tutor (um homem de sua família). Elas

\footnotetext{
5 Dictionnaire des Sciences économiques et sociales, dirigido por Ph. Deubel, M. Montoussé, Rosny 2003, p. 304-305: os direitos civis são os direitos universais de que gozam todos os indivíduos independentemente da idade, do sexo e da nacionalidade (liberdade de expressão, de pensamento, de religião, de propriedade, etc.). Os direitos políticos (ou direitos civis ou direitos de participação) são aqueles que permitem que um indivíduo participe do exercício do poder político (direito de votar e de ser eleito, essencialmente). A estes direitos estão associados deveres (pagar impostos).

6 A ideia de descentralizar a política ecoa o método antropológico como tem sido usado, entre outros, por M. Strathern (1988). Sobre este método, ver LEBNER, 2016, pp. 117-150. Para a Antiguidade Clássica, ver LORAUX, 1993, pp. 23-39.
}

7 A lista poderia ser estendida: politeiai, no plural, pode designar as ações conduzidas pelos poderosos para o benefício ou contra os interesses da cidade, ou "política" no trivial sentido atual (ver Démosthène, $3^{\text {ime }}$ Philippique, 2) e politikos, o que designamos como "o estadista" (ARISTÓTELES, Política, 1278b3). Para um estudo preciso, consultar BORDES, 1982. 
não teriam sido jamais cidadãs, ao menos de acordo com o sentido moderno. ${ }^{8}$

A ideia da exclusão das mulheres gregas da organização antiga foi validada por especialistas no campo, no domínio francófono notadamente, com as fórmulas bem conhecidas de Pierre Vidal-Naquet designando a cidade como um "clube de homens" ou as de Nicole Loraux afirmando que não havia "cidadã" e sim "ateniense", e que "o cidadão ateniense podia então ser simplesmente definido como aquele que, dos dois lados, tinha pais cidadãos: o seu próprio pai e o pai de sua mãe" (VIDAL-NAQUET, 1991, pp. 267 288; LORAUX, 1981, p. 121). Essa última sutilmente mostrou, como Yann Thomas definiu em seu capítulo do volume 1 da História das mulheres no Ocidente, que a "divisão dos sexos" era o cerne do pensamento político e imaginários dos gregos (THOMAS, 2002, p. 139). A polaridade masculino/ feminino era então central para expressar de maneira simbólica, explica Nicole Loraux, a operação geral da divisão. Esta se manifesta na psychè individual - identificada pelos desejos, expressóes, comportamentos que podem ser socialmente qualificados como femininos ou masculinos - ou na ordem social e política - como na guerra que opõe combatentes e não-combatentes, heróis e covardes. ${ }^{9}$ Assim, como, para o (a) historiador (a), passar deste registro metafórico e antropológico no qual o "feminino" frequentemente serve para discriminar - pelo verbo - alguns homens dentre outros, ao registro das capacidades sociais, isto é, à discriminação pelo direito que, desta vez, opõe indivíduos segundo seu sexo? Como articular "representações" e "práticas", para utilizar as categorias das pioneiras da bistória das mulheres?

Os trabalhos realizados desde o aparecimento do volume 1 da História das mulheres no Ocidente, notadamente na linha da contribuição de Giulia Sissa sobre Aristóteles e, mais geralmente, os ricos trabalhos sobre o olhar dos médicos antigos sobre as mulheres ${ }^{10}$, sublinharam o caráter sexista e misógino da produção textual da antiguidade grega. Certo número de poetas, a começar por Hesíodo, ao qual podemos associar Simônides de Amorgos, Aristófanes ou os poetas trágicos, frequentemente lembram: os homens têm vilipendiado

8 Para posições diferentes: THOMAS, 2002, pp. 131-200; MOSSÉ, 1993, pp. 63-64. Todos são confrontados com um problema de tradução onde a linguística e a cultura entram em jogo, como o atestam as diferentes formulações utilizadas dependendo se o pesquisador é francófono ou anglófono. Ver a este respeito o capítulo "Full citizens: female", KAMEN, 2013, pp. 87-93.

9 Se a leitura da diferença dos sexos como metáfora estruturante para pensar a política manifesta uma herança que remonta à Claude Lévi-Strauss, a maneira como Nicole Loraux aborda a questão das identidades individuais vem de uma abordagem devida à sua leitura de Freud que havia apresentado os componentes mistos das identidades psíquicas, daí a importância, em N. Loraux (1989, p. 13 e 23-26), do conceito de "mistura".

10 Para uma síntese recente: BONNARD, 2013, pp. 21-39. 
as mulheres - isoladas como um grupo distinto e hostil aos homens - por seu caráter violento, falador, lascivo, guloso, ladrão etc. Para não escapar dos nosso propósito, lembro-me de um célebre relato reportado por Santo Agostinho citando Varrão, o erudito romano que viveu no século I a. C. Este relato se tornou um argumento central da demonstração de Nicole Loraux sobre a exclusão das mulheres de Atenas do espaço político na época clássica.

Segundo Varrão, as atenienses foram excluídas do domínio político após um conflito que opôs a deusa a Poseidon na disputa pela posse da Ática. Mais numerosas que a voz dos homens, foi seu voto unânime que permitiu a Athená se tornar a deusa políades da cidade. Mas, para aplacar a cólera do deus vencido, os atenienses decidiram, diz Varrão, excluir para sempre as atenienses do voto, e proibir-lhes a transmissão de seu nome e se designar como atenienses.

Ora, como mostrou Cynthia Patterson em 1986, o relato reportado por Santo Agostinho associa diferentes ingredientes da tradição mítica antiga, inovando em certos pontos. Neste caso, a votação feita pelos habitantes da Ática, homens e mulheres, e as sanções tomadas contra as últimas, não tem nenhuma atestação anterior ao século I a. C. Isso levou C. Patterson a interpretar o texto de Varrão como um exercício erudito, isto é, uma variação mitográfica da produção sexista precedentemente evocada (PATTERSON, 1986, pp. 49-67). ${ }^{11}$ Além disso, a situação que o relato supostamente explica os três interditos que afetam as mulheres - não estão de acordo com a realidade história conhecida. Com efeito, se as atenienses eram de fato excluídas do voto na Atenas clássica, elas podiam transmitir seu nome a seus filhos. Certamente, comparado ao patronímico, o uso do matronímico (mêtrothen) é raro (SCHMITT PANTEL; CUCHET, 2015). Contudo, a regra geral da denominação grega antiga, ao contrário da prática romana do cognomen transmitido pelo pai a todos os seus filhos, acrescida do praenomen pessoal, é a do nome único atribuído pouco tempo após o nascimento por seus pais. Essa atribuição era feita segundo regras que, em geral, alternavam um nome do ramo materno com um nome do ramo paterno. Enfim, como Anne Jacquemin lembrou em um artigo de 2005 que estuda as dedicatórias inscritas em ofertas depositadas por atenienses em Delfos, as mulheres de Atenas eram realmente chamadas de atenienses (JACQUEMIN, 2005, pp. 337-347).

A questão dos "direitos políticos" era uma oportunidade, especialmente para Nicole Loraux, de fazer interagir simultaneamente o registro simbólico e o registro institucional (segundo o relato de Varrão): a exclusão das mulheres nos planos institucional e mítico; a centralidade psíquica da distinção dos sexos e das operações - mais ou menos problemáticas - da mistura dos 
gêneros masculino e feminino. Desde então, as abordagens dos especialistas da antiguidade se diversificaram muito. Ao estudo dos textos derivados da tradição manuscrita se juntou o estudo dos textos oriundos de descobertas arqueológicas e produzidos em suportes variados: papiros, inscrições em pedra, metal ou cerâmica, sem contar aquelas que lançam mão de objetos e de configurações espaciais. Um novo domínio de pesquisa é revelado, após a tenacidade de pioneiros particularmente ativos e produtivos, o dos jurigrecistas. ${ }^{12} \grave{A}$ época da História das mulheres no Ocidente, o direito antigo conhecido era sobretudo o direito romano, e os especialistas do mundo grego eram pouco numerosos. De fato, a antiguidade grega, contrariamente ao império romano, não produziu um Digesto do conjunto de regras e direitos aplicados no mundo helenófono. À fragmentação política do mundo grego correspondia uma fragmentação dos direitos e da documentação. Mesmo em Atenas no século IV a. C., da qual dispomos de um corpus de discursos jurídicos, sabemos que o direito não existia para além das práticas litigiosas às quais se referia. Em outras palavras, os discursos pronunciados nos tribunais áticos se dedicam, todos eles, a discutir, modificar e, mesmo, inventar uma resposta judiciária para os casos submetidos. Se semelhanças e características comuns entre diferentes resoluções discutidas diante dos tribunais áticos do século IV e os códigos jurídicos conhecidos desde a Creta arcaica até o Egito ptolomaico justificam a expressão, nenhum caráter sistemático é detectável naquilo que se designa como direito grego. No que concerne ao fato político, há muitas diferenças. Para responder às questóes relevantes desse domínio, historiadores, filósofos e cientistas políticos se voltam espontaneamente a Aristóteles, em torno de um importante ensaio baseado em um estudo analítico dos sistemas políticos conhecidos no mundo grego no fim do século IV a. C., o tratado Tôn politikôn. É o próprio Aristóteles que fornece a definição mais estrita daquilo que nós nomeamos "direitos políticos"

\section{Aristóteles e a Cidadania, o estatuto e as funçóes políticas (ARChai politikai)}

No tratado sobre as coisas políticas (Tôn politikôn), Aristóteles define o cidadão como "aquele que pode participar do poder deliberativo (archê

\footnotetext{
12 É necessário destacar o papel dos trabalhos coletivos conduzidos como parte do Simpósio internacional de direito grego e helenístico, reunido pela primeira vez em setembro de 1971, sob os auspícios do Zentrum für interdisziplinäre Forschung da Universidade de Bielefeld. Em último lugar: Symposion 2013: Vorträge zur griechischen und bellenistischen Rechtsgeschichte, (Cambridge MA, 26.-29. August 2013). Akten der Gesellschaft für Griechische und Hellenistische Rechtsgeschichte, 24, editado por M.Gagarin, A. Lanni Wien 2015.
} 
bouleutikês) e do poder judiciário (archê kritikê) », uma fórmula resumida na expressão archai politikai geralmente traduzida como "direitos políticos", "encargos políticos" ou "funçóes políticas" e na qual o componente archê, que indica o poder dividido entre os cidadãos, tem um lugar preponderante (ARISTÓTELES, Política, III, 1275b 18-19)13. As mulheres não são interpretadas, nesta passagem de Aristóteles, como cidadãs, ou pelo menos como cidadãs em sentido estrito: elas não têm direitos (archai). ${ }^{14}$

O próprio Aristóteles, porém, e sobretudo após a primeira afirmação, acrescenta que esta definição é contradita pelas práticas observadas: "na prática, diz ele, o cidadão é aquele que nasceu de dois cidadãos, um pai cidadão e uma mãe cidadã”. Aristóteles usa então duas palavras formadas sobre o mesmo radical, polit-, uma declinada no masculino (politès), a outra no feminino (politis). Esta segunda definição, baseada na observação das práticas, sublinha o fato de que, na Atenas dos anos 330-320 a. C., a cidadania é sobretudo um estatuto ${ }^{15}$ que se aplica a homens e mulheres e lhes dá um direito fundamental (sob a condição de respeitarem as regras) o de produzir cidadãos dos dois sexos. A organização da filiação, que passa pela instituição do casamento legítimo, ${ }^{16}$ é o fundamento do estatuto do cidadão/cidadã. A capacidade de gerar crianças cidadãs é o direito político fundamental reservado aos cidadãos/cidadãs.

Ao enunciar em uma mesma frase duas afirmações que nos parecem contraditórias (as mulheres não têm direitos políticos; as mulheres são cidadãs), Aristóteles constrói a ambivalência da cidadania: ela se apresenta ao mesmo tempo como um estatuto, ligado ao reconhecimento da filiação legítima - e esta é a definição resultante da observação das práticas -, e um conjunto de funções que são também privilégios - e esta é a definição derivada da análise classificatória de Aristóteles.

Pesquisas conduzidas com base em decretos cívicos honoríficos analisam atualmente a complexidade das funções efetivamente incluídas no estatuto cidadão e às vezes distribuídas, de maneira parcial, a não-cidadãos, confirmando

13 As competências do cidadão, e seus direitos, nesta definição, englobam participação na Assembleia, no Conselho, nos tribunais e nas magistraturas específicas (arconte, estratego, tesoureiro, etc). Ver também ARISTÓTELES, Política, III, 1279a 8-9.

14 Aristóteles (Política, III, 1275a19 e 22) precisa que sua pesquisa incide sobre o cidadão em sentido estrito ( $\left.\dot{\alpha} \pi \lambda \tilde{\omega} \varsigma \pi \mathrm{o} \lambda i \tau_{\eta}\right)^{\prime}$, que é definido como 'aquele que participa do poder de julgar e

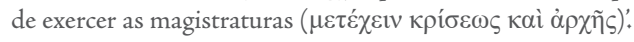

15 O termo é muito discutido. Eu ficarei com a definição de Hunter (2000, pp. 1-19). Observamos que contrariamente aos direitos, o status não recua. Ele é adquirido por nascimento e para sempre.

16 Existem diferentes formas de união: CANTARELLA, 1997, pp. 97-111; C. Leduc (pp. 309. 382) abriu caminho para pesquisas nessa área: recentemente, DAMET, 2015. 
o que os documentos narrativos da época clássica já demonstraram: a questão da cidadania é a participação nos negócios comuns, uma participação que implica direitos ou capacidades bem mais amplamente definidas que os archai politikai de Aristóteles. ${ }^{17}$ Mas, segundo os documentos levados em conta e a formação dos historiadores, a definição das funções - os famosos "direitos" dos cidadãos - é extremamente variável.

\section{OS TIMAIः HONRAS, DIREITOS E OBRIGAÇÕES}

Segundo estudos recentes, uma distinção operatória entre os documentos da prática política (discursos dos oradores áticos, inscrições públicas) é aquela que opõe os epitimoi aos atimoi, em outras palavras, aqueles que tem todas as honras $(\text { timai })^{18}$ e aqueles que são delas privados. ${ }^{19}$ Entre os dois polos, há uma importante gradação de situações para os cidadãos que sofrem privações parciais ou para os estrangeiros que, ao contrário, às vezes adquirem direitos. ${ }^{20}$

Entre os documentos da prática política ateniense do século IV a. C., apenas um, um discurso de Andócides pronunciado no início do século IV, detalha de maneira exaustiva os direitos dos cidadãos (timai) envolvidos em processos de perda de direitos: confiscação dos bens, exclusão dos santuários e das festas, interdição de comércio em certas áreas, interdição de tomar a palavra na assembleia, interdição de ser sorteado para participar do Conselho (Boulè) (ANDÓCIDES, Sobre os mistérios, I, 73-76). ${ }^{21}$ Essas diversas

17 Cf . MÜLLER, 2014, pp. 753-775. Para documentos do período clássico, ver Bordes (1982, pp. 39-47) e, para uma perspectiva mais ampla, Schmitt Pantel (1987, pp. 279-288; 1992, pp. 233-248, p. 234): “Devolver um lugar as práticas coletivas na explicação histórica geral pode ter conseqüências inesperadas: como, por exemplo, o dever de se interrogar sobre o conteúdo de categorias que nós acreditávamos estar claramente estabelecidas como a do político".

18 Os documentos designam como timai o que nós designaríamos como privilégios, às vezes honras, e também 'direitos', que podem advir do nascimento, da idade ou do sexo, e mesmo serem adquiridos por decisão do povo. Esses direitos também podem ser perdidos por decisão do povo.

19A fórmula para conceder a cidadania é claramente expressa no primeiro decreto deste tipo conhecido em Atenas: refugiados da cidade de Platéia, que foram acolhidos em Atenas no início da Guerra do Peloponeso, serão 'epitimoi como os outros Atenienses', em outras palavras, como são os Atenienses em virtude de seu status de Atenienses (KAPPARIS, 1995, pp. 359-378 e pp. 376 377). Os Plateenses tem o privilégio de 'compartilhar a cidade' (pólis), para acessar os timai: direito de participar de festivais religiosos acessando os santuários, direito de dar sua filha em casamento legítimo, direito de possuir terra, etc. O detalhe das ocorrências destes termos (provenientes do TLG) é dado por M. Canevaro (2013, p. 203, n. 70).

20 Principalmente no período helenistico e imperial. Ver Müller (2014, pp. 768-773).

21 Para uma visão geral da bibliografia, do discurso e da passagem em questão: AZOULAT, 2017. 
penalidades sublinham que a perda de direitos atingia toda a esfera social. Nenhuma distinção é feita entre direitos políticos (no sentido aristotélico dos archai politikai), as vantagens econômicas e os privilégios jurídicos. As sanções têm motivos variados que são expostos por Andócides: malversação financeira em relação ao tesouro público, ação sacrílega em relação aos deuses, covardia na guerra etc. Este documento da prática revela também uma concepção muito ampla dos timai que engloba tanto o político quanto o social (segundo o sentido e as distinçóes contemporâneas). O direito de participar das assembleias e tribunais, assim como a capacidade de exercer as magistraturas não são distinguidos como direitos específicos, nem a fortiori apresentados como superiores a outras modalidades de participação na vida social. Os timai não se reduzem aos archai politikai.

\section{As MUlHeres DotAdAS DE TIMAI}

Um discurso de Ésquines datado em torno de 345 apresenta o caso interessante de uma atimia relativa a mulheres. Tratava-se de discutir o caso de Timarco, um cidadão engajado na política ao lado de Demóstenes e acusado por Ésquines de se prostituir e levar uma vida de prazeres, e Ésquines cita uma lei atribuída a Solon que proibia qualquer adorno à mulher que fosse surpreendida em adultério (moicheia) e que lhe proibia de participar de cerimonias religiosas públicas. A lei previa, diz Ėsquines, que se, a despeito desta proibição, a mulher culpada participasse das festas ou usasse ornamentos, qualquer pessoa podia lhe arrebatar, com suas vestimentas, e lhe bater (sem lhe causar a morte, nem mutilá-la). Segundo as palavras de Ésquines, o legislador quis assim atingir a mulher culpada com a pena de atimia, a fim de lhe tornar a vida insuportável. ${ }^{22}$

Em outro discurso, quase contemporâneo, a mesma lei é citada diferentemente (DEMÓSTENES, Contra Neera, LIX, 87). ${ }^{23}$ O termo atimia é então reservado para descrever a sanção destinada ao esposo que persistisse em viver com uma mulher culpada/vítima de um adultério. Para este último, as sanções (interdição em santuários e proibição de manifestar publicamente seu status), podiam ser consideradas, contudo, como uma atimia parcial posto que aparecem na lista de Andócides.

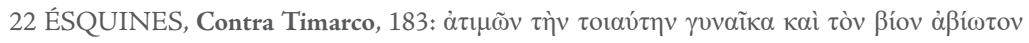

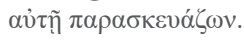

23 Segundo Canevaro (pp. 191-192), o texto autêntico da lei de Sólon, conhecido em Atenas nessa época, é aquele transmitido no manuscrito de Ésquines que evoca a atimia da mulher. 
Como sublinharam Vincent Azoulay e Paulin Ismard em um artigo no prelo, uma privação de honras (atimia), só poderia atingir uma mulher que pertencesse à categoria dos indivíduos dotados de timai (AZOULAY, 2017). Aquelas que são abarcadas pela lei de Solon citada por Ésquines são aquelas cuja sexualidade é supervisionada, ou protegida, dependendo do ponto de vista, e que um discurso de Demóstenes enumera: as esposas, mães, filhas ,irmãs ou concubinas do chefe da casa (DEMÓSTENES, Contra Aristócrates, XXIII, 53; MACDOWELL, 1963, pp. 74-77). Estas mulheres são destinadas a produzir filhos livres, isto é cidadãos, na casa ancestral. A gravidade do crime de moicheia, geralmente traduzido por adultério (mas o significado é menos sexual que patrimonial, pois não visa às relações extraconjugais de tipo homossexual nem as relações de tipo heterossexual com uma mulher escrava), não levam em conta uma eventual violência (violação) sofrida pela mulher. $\mathrm{O}$ crime pode dizer respeito a uma esposa ou a uma jovem não casada, bem como a uma viúva. Importa somente a ofensa feita ao chefe do oikos, o responsável pela descendência das mulheres livres de sua casa.

Para o público de Ésquines, a mulher adúltera, a que detinha os timai que lhe foram retirados, pertencia ao grupo da casa cidadã. Ela não podia ser escrava porque ninguém tinha o direito de matá-la ou mutilá-la: seu corpo é livre. Poderia ela ser estrangeira, acolhida na casa como concubina? É provável que não, pois as sanções contra os metecos culpados de transgressões (homicídio de um cidadão, fraude sobre seu estatuto pessoal ou de um membro de sua família) são a morte ou a venda como escravo, um tipo de alterativa à atimia que, mesmo parcial, atingia apenas os indivíduos cidadãos. A estrangeria recebia provavelmente outras marcas de infâmia para que sua vida se tornasse "insuportável". Esta expressão evoca para nós diversas práticas (depilação da genitália, cegueira, desfilar acorrentada pela cidade, raphanismos...) que sabemos ter atingido seus amantes masculinos (CANTARELLA, 2005, pp. 236-253; SCHMITT PANTEL, 1981, pp. 117-122). A mulher, culpada ou vítima, não podia portar os signos da sua riqueza e de seu estatuto social, as joias.

Em meados do século IV a. C., teria sido normal falar em privação de direitos, atimia, de uma cidadã, no contexto institucional e diante dos jurados do tribunal de Atenas. Se o caso era raro, senão único na nossa documentação, isso talvez se explique pelo menor interesse pelos negócios que concerniam às cidadãs pelos cidadãos que na maioria resolviam suas contas entre si.

Os indivíduos que dispunham da integralidade dos direitos ou das honras, os epitimoi, são aqueles que se comportam segundo as regras da comunidade : pertencimento a uma família identificada como ateniense, 
filiação legítima, concordância da idade com a função exercida, concordância do sexo com a função exercida, modo de viver conforme as regas (sophrôsunê). As mulheres cidadãs são submetidas às mesmas restrições de comportamento que os homens cidadãos, restrições de adequação de sua pessoa com as regras de atribuição das funções cívicas. Elas deviam ser reconhecidas como filhas legítimas por seu pai cidadão, ser apresentadas na phratria do pai. Elas não podiam, por causa de seu sexo, ser juradas, bouletas ou magistradas (exceto os sacerdócios). Na medida em que elas respeitavam essas regras, dispunham de todos os timai. As cidadãs, salvo os casos de confisco pronunciado de modo individual, são de fato parte dos epitimoi (MARCHIANDI, 2011, pp. 66-70). Pelo nascimento ou o ato de dação de um esposo (egguê), as ofensas que elas cometem ou sofrem, como as honras que elas recebem, recaem não somente sobre elas, mas também sobre sua casa como um todo e, particularmente, sobre seu chefe.

\section{Estatuto das pessoas, estatuto da casa}

Os especialistas do direito sempre trataram as categorias jurídicas como categorias de pessoas, usando um masculino genérico. ${ }^{24}$ Ora, nas cidades antigas, o direito das pessoas era dependente da filiação, salvo o caso, muito raro na época clássica, da aquisição dos direitos por decreto (como os Plateenses em 427). ${ }^{25} \mathrm{O}$ estatuto das pessoas era então dependente do estatuto da casa, a oikia, o que sublinha a questão levantada quando do exame dos arcontes entrando no cargo. Os atenienses perguntavam aos candidatos "se eles possuem tumbas familiares e onde elas se localizam, e se eles se comportam corretamente com seus pais" (ARISTÓTELES, Constituição de Atenas, 55.3; MAFFI, pp. 254-289). Trata-se sempre dos túmulos dos homens e das mulheres da família, dos cuidados em relação aos ancestrais maternos e maternos, e nunca exclusivamente aos pais. ${ }^{26}$

Enquanto membros legítimos da casa, as cidadãs jamais são tratadas como estrangeiras, e menos ainda como escravas. No tratado sobre a Constituição de

24 No capítulo consagrado ao "Status Pessoal", a classificação de MacDowell (1978, pp. 67 83) distingue os "cidadãos por nascimento", "cidadania conferida a estrangeiros", "proscritos e desfavorecidos", "estrangeiros", "estrangeiros residentes (metics)", "estrangeiros privilegiados", "escravos", "libertos", "escravos públicos".

25 Osborne (1981-1983) com a lista dos decretos de concessão de cidadania conhecidos (IV 210-21): os 4 primeiros casos datam entre 480 e 322. Ver também S. Todd (1993, pp. 167-200).

26 O recente dossiê Mères grecques organizado por F. Gherchanoc (2015), documenta de maneira útil o lugar das mães no dispositivo cívico. 
Atenas, atribuído à escola de Aristóteles, o tribunal do Palladion é descrito como o lugar onde são julgados todos os homicidas sem premeditação ${ }^{27}$ assim como os assassinatos de escravos, de metecos e de estrangeiros. Geralmente se esquece de precisar que as mulheres estavam incluídas em todas as categorias estatutárias descritas pelo autor do tratado: mulheres escravas, metecas, estrangeiras. Os assassinatos de cidadãs, como de cidadãos e de seus filhos menores, eram tratados no Areópago, e não no Palladion, o tribunal reservado aos estrangeiros. ${ }^{28}$ A transposição mítica dada pela Orestia de Ésquilo em meados do século $\mathrm{V}$ em Atenas o testemunha: o tribunal do Areópago é instituído para julgar o assassinato de Clitemnestra por seu filho Orestes.

Que as cidadãs eram responsáveis por seus atos perante a justiça, o processo movido por Apolodoro contra Neera no fim dos anos 340 nos mostra. Neera supostamente não era a ateniense que pretendia ser, e sim, acusa Apolodoro, uma antiga escrava, estrangeira em Atenas, que fazia passar seus filhos por cidadãos graças à cumplicidade do ateniense Stephanos (DEMÓSTENES, Contra Neera, LIX, 85-87). Como prova, o acusador ataca diretamente a ela, e não a seu marido, Stephanos, cuja qualidade cidadã não é nunca posta em causa. Neera se arriscava à venda no mercado de escravos, porque a lei previa, em caso de fraude averiguada sobre o estatuto de cidadão, que o indivíduo, homem ou mulher instalada(o) em uma casa de cidadãos enquanto parceiro sexual legítimo apesar de não sê-lo, fosse acusado nos tribunais e, se fosse reconhecido culpado, vendido como escravo. O cidadão que recebia uma estrangeira como esposa legítima era penalizado com uma multa de mil dracmas (DEMÓSTENES, Contra Neera, LIX, 16). Um cidadão que desse em casamento uma estrangeira a outro cidadão, fazendo-a passar por cidadã sofria, por sua vez, uma privação de direitos (atimia) incluindo a confiscação de sua propriedade (DEMÓSTENES, Contra Neera, LIX, 52). $\mathrm{O}$ caso da cidadã que recebesse um estrangeiro como esposo legítimo (então cidadão) não é mencionado. Não é o caso de se surpreender: o crime não é o casamento, mas o reconhecimento dos filhos. Ora, isso depende do parceiro masculino, responsável pela declaração que dava diante de todos de ser o pai cidadão.

As cidadãs podiam, além disso, falar diante dos atenienses: é conhecido o caso de Agariste, esposa do Alcmeonidas, que denunciou ao Conselho três cidadãos que teriam participado da paródia dos Mistérios em Atenas, em

27 A noção (bouleusis) é mais complexa: ARISTÓTELES, Constituição de Atenas, 57.3 ; MAC DOWELL, pp. 58-68.

28 As crianças são percebidas como membros da cidade, de status cidadão: Plutarco, Etiologias gregas 22 sobre o "túmulo dos filhos" em Cálcis (MAC DOWELL, p. 69) 
415, e que Andócides fez comparecer ao tribunal em 399 (ANDÓCIDES, Sobre os Mistérios, I, 16). A sobre-representação de cidadãos em relação às cidadãs no processo se explica, sem dúvida, pelo contexto dos documentos que emanam de uma prática política masculina.

O círculo dos membros legítimos da cidade (designados com o etnônimo atenienses, coríntios, coríntias etc.) reunia aqueles que dispunham dos timai, os "direitos políticos" por seu nascimento, seu reconhecimento legitimo e seu crescimento no quadro das instituições cívicas. Esses direitos eram distribuídos, e regra geral, herdados, segundo diferentes critérios: o nascimento de pais atenienses, o "bom nascimento" distinguia aqueles e aquelas que podiam aspirar a certos sacerdócios, os sacerdócios hereditários. A riqueza permitia a alguns agir com munificência e ser honrados por isso. A idade era um critério importante para ocupar muitas funções. O sexo traçava, enfim, uma distinção fundamental entre os adultos atenienses: às mulheres não era permitido tomar a palavra na assembleia, votar, ser magistrada ou participar do exercido cívico.

A desigualdade de fundo entre cidadãos e cidadãs que, segundo seu sexo, não tinham acesso ao mesmo conjunto de funções públicas não pode mascarar a inclusão das cidadãs na cidadania, se dermos ao termo seu sentido antigo de participação na politeia, na cidade e se levarmos em conta que esta participação encontra sua justificativa no pertencimento a uma casa cidadã. No entanto, a desigualdade de acesso às funções cívicas segundo o estatuto individual indica que a diferença sexual constrói, no interior da casa, uma polaridade estrita entre cidadão/cidadã.

\section{Direitos POLÍticos: OS ARCHAI POLITIKAI DOS CIDADÃos E OS TIMAI dE CIDAdÃos E CIDAdÃS}

Ao isolar a dupla prática da deliberação e do judiciário, designando-a como sendo aquela que, stricto sensu, define o cidadão, Aristóteles voluntariamente distingue as práticas observadas: ele produz literalmente uma definição restritiva da cidadania, ao limitar os direitos ao exercício das funções altamente segmentadas, as da participação ativa em assembleias e tribunais. ${ }^{29}$ Aristóteles valida assim a ideia de uma distinção entre atividades deliberativas e judiciárias, e tudo o que resta (que ele não detalha). É por

29 Sobre as nuances de sentido de timê (Direito, honra, cargo político), veja a ambigüidade de Aristóteles (Política, 1278a35) que joga com o significado homérico do termo que englobava então honras variadas, de tipo aristocrático, e o significado estreito que promove pela definição restrita aos cargos públicos (desta ambiguidade decorre as divergências nas traduções (MÜLLER, p. 761 n. 45). 
derivação lógica que ele diferencia os archai politikai, os deveres políticos dos cidadãos chamados a participar das assembleias e exercer magistraturas, dos timai, conjunto de direitos ou privilégios próprios aos atenienses e suscetíveis de lhes serem retirados. ${ }^{30}$

Se Aristóteles restringe o campo dos direitos políticos aos cargos públicos que são a faculdade de julgar e a de comandar (krisis e archê), é porque ele optou por focalizar em seu estudo a questão da divisão do poder (archê) em detrimento de uma análise das modalidades de participação (metechein) e porque retrata o cidadão segundo os critérios de uma cidade na qual o poder de deliberar e julgar é atribuído a todos (magistrados dito generalistas) sem se limitar àqueles que declaravam competências específicas, como ocorre nas oligarquias (ARISTÓTELES, Política, III, 1275b 11-29). O objetivo de sua pesquisa é definir o indivíduo que, em sentido estrito (haplôs) segundo sua expressão (ARISTÓTELES, Política, III, $1275 \mathrm{a} 19$ e 22) exerce tais funções. O objetivo é também definir o "bom cidadão", aquele que é capaz de, ao mesmo tempo, obedecer e comandar bem (ARISTÓTELES, Política, III, 1277a 2527 e b 13-16). Aristóteles (Política, III, 1277b 20-25) compara a posição deste último àquela ocupada pelo marido, de uma parte, e pela esposa, de outra. ${ }^{31}$ Tal imagem do cidadão (tendo ou não as virtudes exigidas) é antes prescritivo que descritivo. O redator anônimo do verbete "Política" da Enciclopédia nomeia também Aristóteles como o primeiro a definir os elementos fundadores de uma "filosofia política", isto é, um saber instituinte da boa conduta "do Estado" (BORDES, p. 16). ${ }^{32}$

Ao expandir a noção dos direitos políticos aos significados sociais das timai, o observador contemporâneo observa que, na Atenas clássica, a prática

30 Aristóteles (Política, III, 1279a8-9), para os archai politikai e 1278a36 e 38 para as timai. A expressão de archai politikai aparece pela primeira vez com Platão (República, 345e [au sg.], 521b ; Leis, 917a).

31 A comparação entre o governante e o governado é da mesma ordem que a estabelecida entre a sabedoria e a coragem de um marido e de uma esposa: "Um marido seria considerado covarde se fosse corajoso apenas como uma esposa corajosa, e uma esposa seria livre demais para falar se tivesse apenas a reserva de um homem de bem desde que o modo de dirigir a casa é diferente para o marido e para a esposa: o papel de um sendo o de adquirir, o do outro, de conservar", uma opinião que não envolve apenas seu autor.

32 De antemão, Platão é o primeiro a ter aberto a reflexão sobre política como ciência (AZOULAY, 2014, pp. 689-719 e pp. 692-694). Notaremos que na Encyclopédie de Diderot e d’Alembert, o termo « política » dá lugar a um longo artigo comentando o substantivo no seu uso no singular: a " política » equivale a "Filosofia política". De Aristóteles à Maquiavel, o redator desconhecido do folheto explica que a política "Ensina os homens a se comportarem com cautela, seja à frente de um estado ou à frente de uma família”. A política, a partir da prática participativa, tornou-se uma ciência da ação (Encyclopédie, 12, 917-919: s.v. política. http://encyclopedie.uchicago.edu/)). 
da ação pública englobava ações da vida coletiva que eram realizados, segundo os contextos, por homens e mulheres. Deve ser lembrado que a cesura política é antes de tudo uma cesura estatutária do corpo social que distingue as casas cidadãs. Os atos da vida coletiva são, em seguida, divididos segundo as variações estatutárias internas ao corpo cidadão: a idade, o sexo, a capacidade econômica ou a dignidade herdada eram elementos dos parâmetros discriminatórios. Além disso, o comportamento individual é igualmente um motivo de distinção social, seja positiva ou negativa (atimia).

No que concerne às cidadãs, a desigualdade essencial advinha de sua exclusão do exército, das assembleias e dos tribunais, bem como das magistraturas. De resto, elas dispunham de direitos comunicáveis na polis, então de timai que são comparáveis, senão equivalentes, àqueles dos cidadãos e que pesquisas futuras devem precisar: participação em festas religiosas, em trocas econômicas e financeiras, direito à proteção jurídica de seus corpos (sempre segundo os critérios dos gregos: a violação, que consideramos como um atentado ao corpo não é interpretada da mesma maneira, já que é considerada como um adultério), à propriedade do solo. Sobre todos esses pontos, o mundo grego não funciona de maneira homogênea, direitos podem ser atribuídos às cidadãs em tal cidade e recusados em outra, assim como há variações de acordo com períodos. ${ }^{33}$

Definitivamente, perguntar pelos direitos políticos das cidadãs permite, em vez de raciocinar em termos de exclusão das mulheres (como se homens e mulheres tivessem sempre e em todas as circunstâncias sido distinguidos como duas categorias absolutamente estranhas uma à outra), historicizar a noção de direito político e, mais ainda, historicizar o próprio fato político. Na Atenas clássica, a participação política era um assunto para pessoas qualificadas por seu nascimento, ou pela decisão do povo, e de um conjunto de timai que são certo número de direitos, não definitivos, ligados tanto ao estatuto pessoal e aos modos de comportamento. Isso explica que indivíduos de estatutos diferentes (sejam cidadãos ou estrangeiros), podem compartilhar timai similares e que indivíduos do mesmo estatuto (cidadão ou estrangeiro) podem não dispor dos mesmos timai. Em todas essas configurações, encontramos mulheres e homens, as primeiras excluídas em bloco dos archai politikai. De fato, quando a política dos gregos se torna um saber e uma ciência - ou mesmo uma filosofia - com Aristóteles mais que com Platão, ao colocar o acento sobre esses archai,

33 Sobre todos esses aspectos é necessário olhar para a documentação da prática e não confiar nas afirmaçôes frequentemente misóginas ou sexistas dos discursos feitos em frente às assembleias ou tribunais por homens que falam para outros homens. As variaçóes geográficas e cronológicas merecem ser estudadas em detalhe. 
uma separação poderosa que se marca em relação às práticas participativas da vida na cidade (polis). E não é um paradoxo menor que na mesma época, quando o hábito epigráfico se desenvolve, as cidades gregas passam a oferecer a cidadania (politeia) mesmo às mulheres. ${ }^{34}$

\section{REFERÊNCIAS}

\section{Documentação Textual}

ANDOCIDE. Sur les Mystères. In: . Discours. Texte établi et traduit par Georges Dalmeyda. Paris: Les Belles Lettres, 1930.

ARISTOTE. Politique. Texte établi et traduit par J. Aubonnet. Paris: Les Belles Lettres, 1960. - Constitution d'Athènes. Texte établi et traduit par Bernard Haussoullier \& Georges Mathieu. Paris: Les Belles Lettres, 1922.

DÉMOSTHĖNE. Contre Nééra. Paris. Les Belles Lettres, 1960.

DÉMOSTHÈNE. Contre Aristocrate. In: . Plaidoyers politiques.

Tome II: Contre Midias - Contre Aristocrate. Paris: Les Belles Lettres, 1959.

ESCHINE. Discours. Texte établi et traduit par Guillaume Budé \& Victor Martin. Paris: Les Belles Lettres, 1927.

Bibliografia

AZOULAY, V. ; ISMARD, P. Honneurs et déshonneurs. Autour des statuts juridiques dans l'Athènes classique'. In : MOATTI; C., MÜLLER, C. (éds.). Les statuts personnels à l'épreuve de l'espace. Paris, Presses Universitaires de Nanterre, 2017.

BARTHÉLÉMY, P. ; SEBILLOTTE CUCHET, V. Sous la citoyenneté, le genre. Clio FGH, 43, 2016, pp. 7-22.

BONNARD, J.-B. Corps masculins et corps féminins chez les médecins grecs. Clio FGH, 37, 2013.

CANEVARO, M. The Documents in the Attic Orators he Documents in the Attic Orators. Laws and Decrees in the Public Speeches of the Demosthenic Corpus. Oxford: University Press, 2013.

CANTARELLA, E. Gender, Sexuality, and Law. In: GAGARIN, M; COHEN, D. The Cambridge Companion to Ancient Greek Law. Cambridge: Cambridge University Press, 2005.

DAVIES, John K. A Wholly Non-Aristotelian Universe: The Molossians as Ethnos, State, and Monarchy. In: BROCK, R.; Hodkinson, S (Eds.). Alternatives to Athens. Varieties of Political Organization and Community in Ancient Greece. Oxford: Oxford University Press, 2000. 
KAMEN, D. Status in Classical Athens. Princeton : Princeton University Press, 2013.

LEBNER, A. La redescription de l'anthropologie selon Marilyn Strathern. L'Homme, 218, 2016, pp. 117-150.

LORAUX, N. Les expériences de Tirésias : le féminin et l'homme grec. Paris : Gallimard, 1989.

MACDOWELL, D. The Law in Classical Athens. Ithaca-London, 1978. Athenian homicide law in the age of the orators. Manchester: Manchester University Press, 1963.

MAFFI, A., Family and property law.In: GAGARIN, M; COHEN, D. The Cambridge Companion to Ancient Greek Law. Cambridge: Cambridge University Press, 2005.

MOSSÉ, C. Le Citoyen dans la Grèce antique. Paris: Nathan,1993.

MÜLLER, C. La (dé)construction de la politeia. Citoyenneté et octroi de privilèges aux étrangers dans les démocraties hellénistiques. Annales HSS, 69/3, 2014, pp. 753 775.

PATTERSON, C. Hai Attikai: The other Athenians. Helios, 13/2, 1986, pp. 4967.

SEBILLOTTE CUCHET, V. Ces citoyennes qui reconfigurent le politique. Trente ans de travaux sur l'Antiquité grecque. Clio FGH, 43, 2016, pp. 187-217.

SCHMIT'T PANTEL, P., SEBILLOTTE CUCHET, V. Mères et politique dans les Histoires d'Hérodote et dans les Vies et les Moralia de Plutarque : pistes de recherche. Cahiers Mondes Anciens, 6, 2015.

STRATHERN, M. The Gender of the Gift. Problems with Women and Problems with Society in Melanesia. Berkeley, 1988. 